\title{
The Brand Management Evaluation Indicators Model of Agri-Tourism Farms: A Core Competence Perspective
}

\author{
Yung-Lun Liu', Li-Ming Ho², Fangyi Liu ${ }^{3 *}$ \\ ${ }^{1}$ Department of Tourism, Chienkuo Technology University, Changhua, Taiwan \\ ${ }^{2}$ Department of Marine Leisure Management, National Kaohsiung University of Science and Technology, Kaohsiung, Taiwan \\ ${ }^{3}$ Department of Information Management, National Taiwan University, Taipei, Taiwan \\ Email: ^fangyiliu@ntu.edu.tw
}

How to cite this paper: Liu, Y.-L., Ho, L.-M. and Liu, F.Y. (2018) The Brand Management Evaluation Indicators Model of Agri-Tourism Farms: A Core Competence Perspective. Open Access Library Journal, 5: e4827.

https://doi.org/10.4236/oalib.1104827

Received: August 6, 2018

Accepted: August 25, 2018

Published: August 28, 2018

Copyright $\odot 2018$ by authors and Open Access Library Inc.

This work is licensed under the Creative Commons Attribution International License (CC BY 4.0).

http://creativecommons.org/licenses/by/4.0/

\begin{abstract}
The purpose of this study was to establish assessment criteria for Taiwan's agricultural leisure brand management. We employed the Delphi method to achieve a consensus of experts' evaluative opinions, and then applied the fuzzy analytic hierarchy process (AHP) to assess the pairwise comparison provided by experts. A consistency test was subsequently performed to establish assessment criteria for agricultural leisure brand management. The relative weights of the agricultural leisure brand management assessment indicators were determined using the statistical software Power Choice. The results of this study were as follows: 1) We developed three primary indicators and eight secondary indicators and established the agricultural leisure brand management assessment model; 2) the primary indicators for the assessment model of agricultural leisure brand management were, in order of importance, brand loyalty, brand awareness, and brand reputation. The findings of this study can be used by agricultural leisure brands as a reference for constructing a competitive management strategy regarding brand management.
\end{abstract}

\section{Subject Areas}

Economics, Sociology

\section{Keywords}

Leisure Farm, Brand Management, Core Competence, Assessment Indicators, Delphi Method, Fuzzy AHP

\section{Introduction}

With the gradual improvement of national income and education standards, 
Chinese people pay more and more attention to the quality of life and leisure tourism activities. However, the development of Taiwan leisure farms has gradually formed a new wave of tourism. Leisure agriculture is the use of agricultural management activities, agricultural equipment, and rural space. The natural environment and rural human resources, combined with tourism, tourism, accommodation, catering, shopping, experience, leisure, an industry to provide people to experience the life of agriculture and rural areas, while caring for farmers and supporting agriculture, improving farmers' income and promoting rural areas. Prosperity is the biggest goal of sustainable agricultural management. However, in recent years, leisure farms have been everywhere, lack of product features, operators often lack the professional ability and a high level of homogeneity, which makes it impossible to highlight the characteristics of individual farms.

Individual leisure farms usually have limited resources and cannot satisfy all the tourist needs of tourists. The attractiveness is not high, so regional or community-based leisure agriculture development is necessary. The characteristics of leisure farms can be different from natural features, landscape features, technical features, cultural features, and human aspects. Whether farm operators can explore their dominant characteristics, give play to the unique biological characteristics, seasonal characteristics, and practical characteristics of rural and agricultural resources to create farm characteristics, rather than introducing foreign things and copying imitation. This will be the key to the leading edge of the leisure farm on the starting line. In particular, the combination of rural cultural characteristics can shape the unique features of leisure farms. If the industry can understand the characteristics of consumers, the decision-making process, and its influencing factors, and effectively distinguish the characteristics and differences of consumers, it can enable the operators of leisure farms to grasp the market more accurately, to adequately satisfy the tourists and create profits in the win-win situation. According to the relevant literature, agriculture is initially a primary industry, agricultural production is a secondary industry, and leisure agriculture is a tertiary industry. The transformation of leisure agriculture can expand the scale and scope of agricultural production, and produce the effect of three-level industry multiplication and addition [1].

\section{Literature Review}

\subsection{Theoretical Foundation of Core Competence}

How to achieve competitive advantage in a competitive environment, [2] believes that core competitiveness is vital to the survival of enterprises, intangible to competitors, difficult to imitate, unique to enterprises, skills, resources, and processes. [3] believes that for enterprises, the core competitiveness is the core technology capability, and the company must have unique and superior professional knowledge, so that others cannot easily imitate, can be called core competitiveness, It can also constitute the company's advantage.

[4] believes that core competencies can provide companies with leading com- 
petitive advantages and create significant customer value. Therefore, for leisure agriculture tourism, it is necessary to find out its own unique and challenging to imitate core resources and capabilities, so that it can bring benefits and value to leisure agriculture tourism and tourists. For the formation of the core competitiveness of leisure agriculture tourism, [5] pointed out that core competitiveness refers to a capability or technology that enterprises define, accumulate and develop to form a sustainable competitive advantage.

At the same time, core competitiveness is an ability that companies can maintain for a long time [6]. According to this theory, [7] points out that a resource with a sustainable competitive advantage must have: 1) resources must create value; 2) resources must be scarce among existing or potential competitors; 3 ) Resources must not be imitated; other resources cannot replace 4) Resources for competitors. [8] also pointed out that competitive advantage comes from its value, scarcity, imitation, and irreplaceability.

\subsection{Theoretical Foundation of Brand Management}

"Brand management" has always been a hot topic, and there are not a few related types of research on brand management. However, most studies still focus on the factors affecting brand equity, and the form factors of brand management are relatively lacking. Therefore, this study looks for evaluation indicators of leisure agricultural brand management from the perspective of core competitiveness. Review related scholars' research on core competitiveness [9] [10] [11] generally applied in enterprise management, while core competitiveness has played an essential role in the successful development of enterprises.

Therefore, after understanding the brand management of leisure agriculture, this study will discuss the evaluation index of leisure agriculture brand management from the perspective of core competitiveness, and analyze the weight of the evaluation index of leisure agriculture brand management, and construct the evaluation model of leisure agriculture brand management, which is applied to leisure. Agricultural development brand management competitive advantage, it is expected that this research can find core competitiveness for leisure agricultural brand management so that leisure agriculture can be sustainable.

The research purposes are: 1) Define the evaluation indicators of the brand management competitiveness of leisure farms; 2) Construct a tiered model of the evaluation index of brand management competitiveness of leisure farms; 3 ) Identify the indicators and relative weights of the evaluation criteria of the leisure farm of brand management competitiveness, and provide them to the leisure farm operators for reference.

Besides, the agricultural related academic researchers put forward another practical research reference in the brand management competitiveness and multi-objective decision-making model.

\section{Methods}

Based on the research purpose, field investigation, interviews with experts and 
scholars, and literature discussion, this study constructs the research method architecture diagram, which is used to explore the evaluation index model and weight of the leisure agricultural brand management competitiveness.

In the leisure agricultural enterprises, the primary purpose of the unique brands, brand trademarks, corporate identification system, information dissemination, popularity, advertising and other resources and capabilities is to improve the visibility of the farm. Therefore, this research refers to this crucial resource and capability as brand awareness. The primary purpose of the farm evaluation, brand goodwill, license, business license, image and other resources and capabilities is to improve the reputation and image of the farm. Therefore, this research refers to this crucial resource and capability as the brand reputation. The primary purpose of customer loyalty, word of mouth and other resources and abilities are to appeal to tourists to revisit and recommend others to travel. Therefore, this study refers to this crucial resource and ability as brand loyalty. Combining these three essential of resources and capabilities, the primary purpose is to enhance the brand image and establish the loyalty of tourists, to become the core competitiveness of the enterprise.

Therefore, this study refers to these three resources and capabilities as the brand management competitiveness. Moreover, establishing the evaluation index of leisure agricultural brand management competitiveness, as shown in Table 1; at the same time define the evaluation index of leisure agricultural brand management competitiveness, as shown in Table 2.

\section{Results}

After the text edit has been completed, the paper is ready for the template. Duplicate the template file by using the Save As command, and use the naming convention prescribed by your journal for the name of your paper. In this newly created file, highlight all of the contents and import your prepared text file. You are now ready to style your paper.

Table 1. The evaluation index of leisure agricultural brand management competitiveness.

\begin{tabular}{|c|c|c|c|}
\hline \multirow{8}{*}{$\begin{array}{l}\text { Brand } \\
\text { management } \\
\text { ability }\end{array}$} & \multirow{3}{*}{$\begin{array}{c}\text { Brand } \\
\text { awareness }\end{array}$} & $\begin{array}{c}\text { Annual advertising } \\
\text { investment }\end{array}$ & $\begin{array}{c}\text { Annual farm advertising investment } \\
\text { amount }\end{array}$ \\
\hline & & Website click rate & Website click rate of leisure farms \\
\hline & & Awareness farms & $\begin{array}{c}\text { The number of people per } 100 \\
\text { people at the farms }\end{array}$ \\
\hline & \multirow{3}{*}{$\begin{array}{l}\text { The brand } \\
\text { reputation }\end{array}$} & Award level & $\begin{array}{l}\text { Professional license and number of prize } \\
\text { items }\end{array}$ \\
\hline & & Customer evaluation & Visitors' overall impression of the farms \\
\hline & & Media evaluation & $\begin{array}{c}\text { Media average annual number of reports on } \\
\text { the farms }\end{array}$ \\
\hline & \multirow[t]{2}{*}{ Brand loyalty } & Customer return rate & Customer return rate of the farms \\
\hline & & Visitors revisiting rate & Customer recommendation rate \\
\hline
\end{tabular}


Table 2. Brand operation of competitiveness evaluation index structure and weight hierarchy structure.

\begin{tabular}{|c|c|c|c|c|c|c|}
\hline Main goal & $\begin{array}{l}\text { First level } \\
\text { indicator }\end{array}$ & Weight & Rank & Second level indicator & Weight & Rank \\
\hline \multirow{8}{*}{$\begin{array}{c}\text { Brand } \\
\text { management } \\
\text { ability }\end{array}$} & \multirow{3}{*}{$\begin{array}{c}\text { Brand } \\
\text { awareness }\end{array}$} & \multirow{3}{*}{0.278} & \multirow{3}{*}{2} & $\begin{array}{c}\text { Annual } \\
\text { advertising investment }\end{array}$ & 0.188 & 3 \\
\hline & & & & Website click rate & 0.342 & 2 \\
\hline & & & & Awareness farms & 0.470 & 1 \\
\hline & \multirow{3}{*}{$\begin{array}{l}\text { The brand } \\
\text { reputation }\end{array}$} & \multirow{3}{*}{0.266} & \multirow{3}{*}{3} & Award level & 0.199 & 3 \\
\hline & & & & Customer evaluation & 0.494 & 1 \\
\hline & & & & Media evaluation & 0.307 & 2 \\
\hline & \multirow{2}{*}{ Brand loyalty } & \multirow{2}{*}{0.455} & \multirow{2}{*}{1} & Customer return rate & 0.461 & 2 \\
\hline & & & & Visitors revisiting rate & 0.539 & 1 \\
\hline
\end{tabular}

\subsection{Level 1 Evaluation Indicators and Weights of Leisure Agriculture Brand Management Competitiveness}

In this study, the evaluation index of leisure agricultural brand management competitiveness is statistically analyzed by Power Choice statistical software. Among the three sub-indicators, the most important factor of the research results in brand loyalty (0.455), followed by brand awareness (0.278), brand reputation (0.266). The research results show that the competitiveness of leisure agriculture brand management is the farm's corporate image, popularity, goodwill, brand image, customer identity and customer loyalty. For leisure agriculture enterprises, for unique brands, brand trademarks, corporate identification systems, information dissemination.

The main purpose of resources, abilities, advertising, and other resources is to increase the visibility of the farm. Although the farm brand is intangible, the farm manages its brand and creates much value for the farm. The brand management competitiveness of leisure agriculture in this study includes brand awareness, brand reputation, brand loyalty and so on. Brand management competitiveness Regarding its secondary indicators, experts and scholars believe that the most important indicator is brand loyalty, which is much higher than the other two indicators. It shows that the services provided by the farm can make tourists' loyalty the essential item.

\subsection{Level 2 Evaluation Indicators and Weights of Leisure Agriculture Brand Management Competitiveness}

Regarding brand awareness, the number of visitors per 100 people on the farm (0.470) is the most important, followed by the visitor's click rate on the farm website (0.342), and finally the farm's annual advertising investment amount (0.188). Regarding brand reputation, the overall impression of the farmer on the farm (0.494) is the most important, followed by the number of media reports on the farm (0.307), and finally the number of farm professional licenses and awards (0.199). Regarding brand loyalty, it is essential for farm customers to 
recommend others to farm tourism (0.539), followed by a farm customer return rate (0.461). For details, see Table 2: Analysis of the weight of the leisure farm of brand management competitiveness index, and at the same time establish the leisure agriculture in the brand operation of competitiveness evaluation index structure and weight hierarchy structure diagram, as shown in Table 2.

\section{Discussion and Implication}

\subsection{Conclusion}

The most critical factor in the competitiveness of leisure agriculture brand management is brand loyalty, followed by brand reputation and brand awareness. Brand loyalty is the most important for customers to recommend others. When a customer has the loyalty to the brand, the branded product can attract customers to continue to purchase, while allowing customers to use it with peace of mind. Besides, when the customer is loyal to the brand, it creates an excellent reputation for the brand, that is, the enterprise organization, and recommends the brand to relatives and friends, forming the strongest and powerful advertising effect of the brand and the company, and attracting new customers come to buy. For the brand management of leisure agriculture, the brand's far-reaching name, the customers' impressive logos, propaganda and related products, supplemented by representative slogans, enhance customer acceptance and brand impression to establish brand goals.

For the establishment of brand awareness, the advantage is that it be more effective when communicating with consumers. If there is no brand awareness, it has to work harder when communicating with consumers, and it may not be able to achieve the desired results. Brand awareness in leisure agriculture can be regarded as a substantial commitment, high-profile leisure farms, and consumers have more definite ideas. When consumers are difficult to judge the quality of leisure farms, they often have the reputation of leisure farms. Alternatively, the amount of advertising on the farm is as the basis for consumption choices, so the higher the visibility of the farm, the higher the brand equity.

[12] talked about the establishment and marketing of brands requires a long-term strategy. Brand building and marketing should establish a long-term vision through the integration process within and outside the organization. Therefore, the establishment of the brand helps to attract consumers. The effectiveness of the brand depends on the integrated marketing strategy of the company. In the highly competitive leisure agriculture market, brand building and marketing strategies play an essential role in attracting customers. [13] also pointed out that under the leadership of the brand, in order to make the brand recognition or recognition project have an effect, it must resonate with the customer, so strategic brand analysis must be carried out: customer analysis, competitor analysis, self-analysis, making the brand differentiate from competitors, also helps business managers understand customers, competitors, brands, and organizations themselves. 
Therefore, to establish the market and positioning of corporate organization brands, it is necessary to conduct overall environmental analysis, consumer behavior analysis, competitor analysis, self-analysis, and market segmentation analysis. Through the meaning of brand management, it can find that brand management is based on the essence of strategic marketing management, and regards brand management as the core competitiveness of business strategy to develop brand marketing activities. Therefore, to implement the brand management of leisure agriculture, it is necessary to enhance the competitive advantage of the enterprise organization according to the strategic marketing viewpoint and the brand management.

\subsection{Suggestions}

According to this study, the most important facets and indicators for the competitiveness of leisure farm brand management are brand loyalty. The results of this research can be referenced to existing operators and future operators. Satisfied customers continue to purchase products or services, form brand loyalty, and even recommend products of the brand to relatives and friends. Therefore, leisure farms must provide customers with better productsand high quality service. Also, this study only establishes the core competitiveness index of brand management for leisure farms. The follow-up researchers can analyze the other indicators of leisure farms, conduct weight analysis on various indicators, and conduct the empirical analysis of various indicators of leisure farms and find out the core competitiveness of each farm.

Leisure agriculture is the practice of experiencing economics in agriculture, and the establishment of customer loyalty begins here. The superior characteristics are designed into an experiential, exciting and humanized experience activity, which integrates the visitors into the situation and touches the five senses of sight, hearing, smell, taste, and touch, which makes them feel beautiful and unforgettable memories. This is the key to the success of future leisure farms through the verification of the development of leisure agriculture in various countries. In the leisure farm area, the overall planning, complementary resources, experience and characteristics, mutual support, joint marketing, and joint planning travel, can provide visitors with a full range of services to enhance loyalty.

Because European holiday farms have become an individual commodity of the tourism industry, Taiwan's leisure agriculture development has feasibility in the leisure market. In the face of retirees, I hope to find a peaceful and comfortable place in the country or abroad to enjoy the local nature and local culture. Taiwan has the advantage of developing a holiday farm. In particular, Japanese tourists generally like Taiwan's beautiful natural environment and firm human touch, so the government can counsel qualified leisure agriculture areas or leisure farms to operate holiday farms that accept long-stay leisure travelers. This will be a new type of leisure agriculture in Taiwan. 


\section{Acknowledgements}

The authors would like to thank the anonymous referees for your valuable comments and suggestions, and the corresponding author Fangyi Liu can be contacted at: fangyiliu@ntu.edu.tw.

\section{Conflicts of Interest}

The authors declare no conflicts of interest regarding the publication of this paper.

\section{References}

[1] Chen, Y., Liu, F., Fang, C.H. and Lin, T.M.Y. (2013) Understanding the Effectiveness of Word-of Mouth: An Elasticity Perspective. Journal of Research in Interactive Marketing, 7, 57-77. https://doi.org/10.1108/17505931311316743

[2] Tampoe, M. (1994) Exploiting the Core Competence of Your Organization. Long Range Planning, 4, 66-77. https://doi.org/10.1016/0024-6301(94)90057-4

[3] Liu, F., Chou, M.Y., Liu, Y.L. and Chen, H.Z. (2013) The Role of MedicalWord-of-Mouth on Sport Therapists: A Patient Psychological Perspectives. Open Journal of Medical Psychology, 2, 7-10. https://doi.org/10.4236/ojmp.2013.24B002

[4] Chen, Y., Liu, F., Ho, L.M. and Lin, T.M.Y. (2012) Development of Word-of-Mouth Elasticity Measures for Tourism Product Categories. Psychology, 3, 722-728. https://doi.org/10.4236/psych.2012.39109

[5] Rahab, R., Anwar, N. and Edy Priyono, R. (2016) Effect of Core Competence on Sustainable Competitive Advantages of Batik Banyumas Small and Meeium Enterprises. Journal of Comparative International Management, 19, 27-45.

[6] Lan, M.Y., Liu, F., Fang, C.H. and Lin, T.M.Y. (2012) Understanding Word-of-Mouth in Counterfeiting. Psychology, 3, 289-295. https://doi.org/10.4236/psych.2012.33041

[7] Barney, J.B. (1991) Firm Resources and Sustained Competitive Advantage. Journal of Management, 17, 99-120. https://doi.org/10.1177/014920639101700108

[8] Liu, F. and Lee, M.J. (2012) Understanding the Island Tourism Image Formation in Taiwan: Via Fuzzy Preference Relations. International Journal of Psychology, 47, 174-174.

[9] Ranchhod, A., Gauzente, C. and Tinson, J. (2004) Marketing Strategies: A Twenty-First Century Approach. Prentice Hall/Financial Times, Harlow.

[10] Guo, Z. (2017) A Study on the Core Competence of the Third Party Logistics Enterprises, Taking Rongqing Logistics as an Example. International Journal of Academic Research in Business and Social Sciences, 7, 222-232.

[11] Liu, F., Chien, I.L., Lan, M.Y. and Chien, Z.M. (2012) Development the Theme Park Brand Equity Model of Taiwan. International Journal of Psychology, 47, 174-174.

[12] Ng, H.S. and Kee, D.M.H. (2018) The Core Competence of Successful Owner-Managed SMEs. Management Decision, 56, 252-272. https://doi.org/10.1108/MD-12-2016-0877

[13] Robinson Jr., R.B. and Pearce, J.A. (2003) Strategic Management. $8^{\text {th }}$ Edition, McGraw-Hill, Inc., $\mathrm{OH}$. 